\title{
Recognition and change: Embracing a mobile policing initiative
}

\begin{tabular}{|r|l|}
\hline Journal: & Journal of Organizational Change Management \\
\hline Manuscript ID & JOCM-11-2018-0305.R2 \\
\hline Manuscript Type: & Research Paper \\
\hline Keywords: & Recognition, Police, Technology, Organizational Change \\
\hline \multicolumn{2}{l}{} \\
\end{tabular}

SCHOLARONE $^{\text {m }}$
Manuscripts 


\section{Recognition and change: Embracing a mobile policing initiative}

Abstract:

Purpose: Radical notions of recognition at work have not been considered widely in respect of organizational change. This article examines the introduction of a change programme across two UK police departments, during which front-line officers were actively involved and consulted throughout its pilot phase. The purpose of this article is to consider the question of whether or not a perceived sense of recognition amongst officers contributed to the success of this initiative.

Design/methodology/approach: The research utilises qualitative data derived from individual interviews, focus groups, and observations, gathered over one-year, within two UK police departments. The data was analyzed thematically. Reflection, and an ongoing discussion with officers, led to a theoretical exploration of recognition, in order to explore the apparent success of the programme.

Findings: Recognition, consisting of a sense of love, respect and esteem, appears to offer a notable impetus to the acceptance of a change programme within a traditionally change averse organization. Resistance to organizational change may be better addressed through a strategy that seeks to actively promote the claims to recognition of organizational members, particularly through the extension of a right to participate within the context of a supportive and protective culture of engagement.

Originality/value: The article utilises the novel, but increasingly utilized, theory of recognition to analyse and explain positive employee involvement in a change programme within the police. This approach helped to achieve change in a widely acknowledged change resistant organization.

Keywords: Recognition, Police, Technology, Organizational change

\section{Introduction}

The participation and involvement literature provides a well-established research stream in the organizational change literature advocating that managers should provide opportunities for employees to have an input regarding proposed changes (e.g. Wanberg and Banas, 2000). In many organizational settings the idea that, at very least, lip service must be paid to consultation, involvement and active participation by employees in any successful change initiative has become such orthodoxy that it is rarely questioned (Furst \& Cable, 2008; Ford et al, 2002). This is problematic, however, in contexts where historically change has been handled poorly (Bordia et al, 2011) and managerial attempts at engagement may be viewed as manipulative (Furst and Cable, 2008). Policing organisations are reportedly characterised by a rank-and-file culture of conservativism and suspicion (Skolnick, 1966; Skogan, 2008), and senior management are less accustomed to the challenges of pursuing complex change management initiatives (White and Robinson, 2014). In such a hierarchical, highly disciplined organization, attempting to introduce change in a context of austerity and declining material resources breeds suspicion that the change simply requires officers to do more for less.

In this article, we set out to consider the question of whether or not a perceived sense of recognition contributed to a successful change initiative that involved front-line police officers in the development and implementation of 'mobile policing technology' - smart phones and tablets operating both bespoke and commercial applications - by two UK police forces. We present a qualitative account of the reaction and responses of officers and explore the positive impact of a felt sense of recognition (Honneth, 1996, 2007, 2012) observed amongst these officers. The employee participation paradigm of change management (e.g. Morgan \& Zeffane, 2003; Wanberg and Banas, 2000) seeks to minimise resistance and negative employee behaviour. Based on our analysis, we move beyond this, to offer recognition as a potential means of initiating change in what has traditionally been considered a relatively static, or change resistant, institutionalized culture (Skolnick, 1966). We argue that the perceived acknowledgement by senior management of the officers' experience and understanding of the demands of the job, particularly under conditions impacted upon by a culture of austerity and declining material 
resources, was central to reducing widespread resistance. This is because it encouraged a genuine engagement with the initiative and indicated a sea change in the relationship between senior police management and frontline officers whereby their emotional well-being, organizational standing, and professional expertise was finally recognized.

\section{Recognition}

A significant body of research has found that increased involvement and participation of employees in organizational change initiatives can lead to more positive perceptions and evaluations of change (Fuchs and Prouska, 2014), including increased openness to change (Wanberg and Banas, 2000); lower resistance to change (Furst and Cable, 2008); higher job satisfaction and organizational commitment (Timming, 2012) and higher trust in management (Morgan and Zeffane, 2003; Timming, 2012). Participation refers to opportunities that allow employees to have an input regarding the proposed changes (Wanberg and Banas, 2000); a wide range of activities which may include participative decision making, consultation or representation which involves varying amounts of power and formality (Morgan and Zeffane, 2003). This literature encourages the use of organizational processes that implicitly aim to recognize employee contribution as a means to nurture psychological ownership of the process of change (Fuchs and Prouska, 2014; Dirks et al, 1996) or to socially exchange organizational support with change compliance (Cropanzano, et al, 2002; Fuchs and Prouska, 2014).

Managerial initiatives to explicitly recognize employee performance or commitment have received, however, something of a negative press in recent years, even amongst those sympathetic to the principles underpinning them (Jenniges, 2018). Certainly, there is a risk that such initiatives which do not align with previous experiences of change within an organization may be viewed as 'hollow gestures' (Bordia et al, 2011) or be perceived as inauthentic in their attempts to recognize employee contributions. Supporting this criticism, Fuchs and Prouska (2014), for example, note how although participant and perceived organizational support were correlated with more positive change evaluations, co-worker support and supervisor support also had a direct relationship to evaluation which was not mediated by participation in the current change initiative.

Similarly, Furst and Cable (2008) found the quality of the existing relationship between employees and their closest manager (in terms of perceived trust and respect) was an important moderating factor in the effectiveness of managerial tactics to reduce resistance to change. Specifically, where the quality of the relationship was poor, consultation was viewed as a tactic to shift problem solving responsibility on to employees. This meant that moves to legitimise change were seen as calculative, and attempts to ingratiate employees were seen as manipulative. On balance, findings on participation and involvement suggest that a generally supportive culture within an organization may be just as important as participation in a specific change initiative. This is problematic in contexts where historically change has been handled poorly and such a culture may not exist. In this context attempts to include employees might be viewed with suspicion.

Recognition theory, however, is grounded in the proposition that the intersubjective development of an emotionally and psychologically healthy subject depends upon their recognition as a worthy individual by other members of their group, society, or indeed institution. Additionally, while the healthy formation of the subject is dependent upon the presence and recognition of others, recognition theory seeks to foster essentially free or autonomous individuals (Honneth 1996). This is premised on the reasoning that it is only through our recognition of others that we are able to fully experience and express our own freedom to recognize or devalue the contributions and identities of others (Fitche, cited in Williams, 1992). Within recognition theory, therefore, individual autonomy and collective cointerdependence are mutually constitutive within the context of successful human relations.

Building on these ideas, as well as those of Marx (1971), Mead (1934) and Habermas (1987a, 1987b), one of the leading contemporary proponents of a recognition philosophy, Axel Honneth, argues that a desire for recognition sits at the heart of the evolution of stable and meaningful social relations that are integral to the functioning of a healthy civil society and successful democracy. Honneth has developed 
a system of thought underpinning how such a desire is both enacted and realized through three distinct, but interdependent, patterns of experience (Honneth, 1996: 93 - see table 1 for more detailed descriptions); namely,

- love/self-confidence - experience of assurance that a loved one will continue to care when independence is demonstrated

- respect/self-respect - being institutionally recognized as a legitimate bearer of universal rights and responsibilities

- social esteem/self-esteem - feeling confident that one's achievements or abilities will be socially recognized as 'valuable' by other members of a society or group.

For Honneth, however, the achievement of recognition is not commonly a passive achievement. Rather, it is a dynamic process and one that necessitates the emergence of certain socio-cultural and political institutions that act as its guarantor. Achievement of recognition will then in turn reproduce such institutional frameworks. Recognition, therefore, represents an engendered emancipatory struggle at both the individual level - in terms of intersubjective relations - and at the institutional level, in terms of the establishment of such institutions that support the mutual valuation and recognition of the status and rights of individual subjects (Marcelo, 2013).

Holtgrewe (2001), in her study of call centre workers for example, has argued that recognition can be understood as providing a normative grammar that underpins both the individual experiences of workers, alongside providing a drive and logic for conflicts between employees and management. This can lead to an improved working environment and sense of valuation for the former and perhaps improved receptibility to change. For Islam (2012), Human Resource Management practice, while often promoting a degree of instrumentality amongst managers, can be underpinned by an ethical acknowledgement of the right to recognition of employees on the basis of an acceptance that they are, by virtue of their voluntary entry into employment contracts, autonomous subjects entitled to dignity and respect; values that should be intentionally promoted through organizational policies, and managerial reward structures.

It is argued here that the application of recognition theory provides a phenomenological device that enables one to capture the lived experiences and understandings of police officers. As such, we employ recognition theory to explain the relative success of the change initiative and those elements of the process that contributed to this. In doing so, we argue that by recognizing and valuing the experience and knowledge of their officers, these two forces not only gained support for the initiative, but also seeded a change in the relationship dynamics between senior police management and those serving on the front line. This approach is potentially informative for similar organizations seeking to undertake change in the face of hierarchical and traditionally resistant cultures. Finally, we reflect perhaps more critically on their limitations within the context of the values also underpinning recognition as a potential philosophy of individual autonomy.

\section{Context and Methods}

Before exploring some of these issues through the data, it is important to re-establish the context of the research. While resistance to change is a well-established focus of much of the existing change management literature (Coch \& French, 1948; Cutcher, 2009; Thomas \& Hardy, 2011), as alluded to earlier, pursuing change within a hierarchical and highly disciplined organization, such as the police, can face particular obstacles. For while it might be assumed that a more widespread acceptance of a command and control approach to both operational and human resource management might serve to advantage change initiatives and instrumental mechanisms for recognition, this appears to be far from the case. Policing, in particular, is reportedly characterized by a rank-and-file culture of inertia and, particularly, suspicion (Skolnick, 1966; Skogan, 2008), both significant impediments to the nurturing of the innovative and accepting mind-set often required for successful organizational change. Yet despite such obstacles, police forces around the world are under increasing pressure to adapt and often 
radically alter their existing practices and cultures. This is due to a host of circumstances ranging from increasing demands for accountability and the impact of 'new public management' (Hoque et al., 2004), through the long-term impact of dwindling financial resources (U.S. Department of Justice, 2011; Grierson, 2017) and the challenges of both international and domestic terrorism (Klausen, 2009). Of particular interest here, is the impact of communication technologies which have proven to be an important resource both for law agencies (Lindsay et al., 2009; Byrne and Marx, 2011-13; Koper, 2015) as well as the criminal fraternity (Surette, 2015).

This contextualises our focus on how two UK police services approached what was, for them, an innovative and challenging organizational change programme underpinned by the introduction of a mobile communications system for front line officers. This innovation was, in large part, an attempt to tackle two pressing and inter-related concerns. Firstly, it sought to address a dwindling resource base due to significant year on year cuts in police funding. Secondly, it aimed to improve the police presence on the streets, which has been negatively affected by reduced officer numbers and increasing demands of desk based administrative duties.

While based on the purchase and distribution of commercially available mobile phones and tablets, combined with the incremental roll out of commercial and bespoke applications, the change process was envisaged by senior management to be far wider in scope. It would impact not only on how frontline officers recorded crime, but how they organized their working days, including restricting face to face contact with other officers and encouraging the aforementioned physical presence of officers within their communities. The introduction of such technologies was envisaged by as facilitating a fundamental step-change in the practices and culture of policing across the two counties.

Having previously undertaken a number of largely unsuccessful attempts to introduce other forms of information technology - such as reinforced laptops and personal digital assistants (PDAs) - there was a stated desire by senior officers to avoid the somewhat clumsy, top-down imposition of technology of past attempts. As such, the notion of a pilot introduction of the technology, led by a small team of committed junior and mid-ranking officers, was proposed as a means by which front-line views and experiences of the initiative could be fed back into its ongoing development prior to a forces-wide roll out.

In what was a particularly innovative decision by the two forces at the time, the officers charged with leading the initiative were given permission to invite a team of academics to monitor the pilot, attend training events, and undertake confidential, qualitative interviews with officers charged with introducing and managing the initiative and taking part in piloting the technology. Our primary research brief was, therefore, concerned with exploring the response of officers to the introduction of this mobile policing platform based on smartphone and tablet technology designed to address the aforementioned policing challenges.

The data for this article was collected over the period of a year - before, during, and after the piloting of the new policing technology - primarily in the form of interviews and focus groups. The aim was to understand the challenges throughout the process through the eyes of those who were experiencing it. Firstly, we conducted four interviews with senior stakeholders and strategic leaders across the two police forces to understand the aims of the initiative and their perspective on the drivers for this. These interviews took place approximately four months before the pilot.

Secondly, we conducted five focus groups with frontline officers. Each group consisted of between 48 officers ( 25 officers were included in total) from a range of front-line services. Focus group members were mid-way through participating in the pilot. The focus groups were led by one of three academic researchers and it was emphasized that their feedback and views would be entirely anonymous. A number of officers expressed openly how refreshing they found it to have an independent researcher facilitate these discussions rather than a superior officer. 
This was important as reporting mechanisms in the police force have traditionally been hierarchical and it emerged very quickly in the discussions that this had prevented the flow of feedback in previous initiatives, generating a notable degree of suspicion about motives and the extent to which their expertise and experience was actually recognized. As such, we began to explore recognition as a theme in our study, in part adapting our questions, analysis and literature reviewing activities to understand how recognition might explain our findings. We encouraged officers to talk more about both the process of their inclusion in the pilot and how the technology was impacting their work routines, their relationships at work, and their perceptions and relationship with the organization. Each focus group lasted between 1.5 and 2 hours.

Finally, six follow up one-to-one interviews were conducted with front-line officers after the pilot had finished. All interviewees were previous focus group participants, and the objective of these interviews was to allow them to reflect retrospectively on the process, having now completed the pilot, and articulate how they felt their input might have helped inform decision making within the organization.

Interviews and focus groups were professionally transcribed verbatim and reviewed by the research team. As interviews were conducted between three researchers, the first stage of the analysis process involved the reading and rereading of all transcripts. At this, and other regular points in the analysis, the researchers met to discuss common themes which emerged from the data, particularly those where opposing ideas or paradoxes emerged. An initial analysis aimed at identifying implementation challenges led to the emergence of three core themes which were: the impact of the legacy of failure, organizational distrust, and need for culture change. These were reported back to the organization in a report and action steps to overcome these challenges were developed by the organization. Our relationship with the project team continued for some time after data collection and this allowed us to analyse further the impact of our involvement as researchers had on the change dynamics moving forward.

Whilst involvement of officers was always central to our interpretation of this data, it was an analysis of the longer-term impact of our involvement which emphasized the powerful role that recognition played in shaping changes in the way which officers viewed the initiative and behaved throughout the process. The very nature of our qualitative approach to this study required us to take a reflexive view of the role which researchers play in socially constructing an officer's interpretation of their experiences. However, the positive reaction of officers to our involvement brought to the forefront our capacity to shape change by providing a mechanism for recognition ourselves. As the study progressed, we refined our analytical strategy drawing on the three-stage process of data reduction, data display, and conclusion drawing described by Miles and Huberman (1994). As such we:

- Utilized a process of open coding to identify officers' initial reactions to the changes, emotions and attitudes towards the organization and the handling of the pilot.

- Searched for common categories amongst these codes and developed second order themes reflecting with a combination of emergent, and increasingly theoretically pre-indicated, priorities pertaining to recognition.

During this process we employed a method of constant comparison between the data, literature on involvement and recognition, and our analysis, by revisiting transcripts and adjusting our analysis over several iterations, with three aggregate themes emerging that reflected the theoretical categories of recognition (see Table 1).

In addition to these interviews, the research team met regularly with the project team and held informal discussions with regard the challenges they faced with the project. The project team members were all relatively junior and therefore faced challenges to their decision making at regular intervals and needed to navigate the hierarchy above them with considerable political skill. These informal discussions were recorded in the form of field notes and were used to contextualize the analysis. Two researchers also observed one of the training sessions for the pilot to understand the technology and the culture of learning in the organization. Various strategy documents were made available to the research team 
throughout the research period and we were also able to follow more public developments around the local and national context of mobile policing in the media throughout the period.

Our theoretical interpretation of the data elucidated the ways in which recognition was enacted and perceived by front-line officers. In the next section of the article, we present an account of how the perceived recognition by senior management of the officers' experience of the demands of the job initiated a change in the relationship dynamics between senior police management and front-line officers (see also table 1).

[Insert Table 1 here]

\section{Findings}

From the outset of the research, it was clear that there existed an acceptance of the need for such technologies, the nature of the equipment being introduced, and the underpinning logic, from officers at all levels. This was particularly true in respect of the business case discourse that had been mobilized by senior officers in that such technology would help improve efficiency and police presence within an increasingly restrictive fiscal environment. Comments made by officers included 'time's money isn't it?', 'if this saves us time, it saves us money', 'it also keeps us more visible out on the streets', and 'by keeping us out there longer, it enables us to perhaps be more efficient'.

It was evident that a number of the officers demonstrated an enthusiasm for the technology itself, believing it was 'about time' police had formal access to it. This was especially striking given the previously documented tendency to resistance by the police to such initiatives (White and Robinson, 2014). Our respondents confirmed that they were no exception to this tendency when it came to previous attempts by the two forces in question to introduce similar technologies, such as PDAs. In fact, our data did reveal a notable concern by both senior and mid-ranking officers leading the initiative about the likelihood of resistance by the front-line, resulting from the legacy of a series of previously unsuccessful attempts to introduce technological solutions to frontline policing problems. For example, the notion that previous initiatives had not been driven by operational officers - alongside the technical failures suggested that there was a lack of esteem amongst senior commanders with regards to the officers' knowledge and accumulated experience as well as their right, as professionals, to legitimately express this.

This, previous lack of recognition, had resulted in an important legacy issue for many officers when it came to their accepting the intentions underpinning the new mobile policing initiative. One constable described this as an ongoing experience across the force in the following terms:

Like everything in this job - whether it be this, whether it be paperwork or anything unfortunately the people who make the decisions haven't been police officers on the frontline; they don't really have a clue what's going on.

Whilst not explicitly articulated by respondents in respect of a sense of recognition, our analysis shows how officers expressed views and opinions about the current initiative that were consistent with our analytical framework. Table 1 illustrates the relationship between patterns or modalities of recognition (Honneth 1996), and our empirical findings. What was also clear, however, was that felt recognition was at least partly a response to a perception that several aspects of the pilot initiative were put into place including, (i) the devolution of authority to mid-ranking and junior officers, (ii) the introduction of a piloting of the technology across a sample of officers with differing duties and responsibilities and (iii) the invitation presented to our team to undertake a series of confidential qualitative interviews. This not only provided a mechanism for legitimate contributions to be made (respect) but equally it demonstrated the value of their experiences with the technology itself (esteem).

By inviting these officers to share and express their experiences and allowing them to locate their professional and operational value within the intermundane spaces of everyday policing, it was felt to 
bestow a quality of esteem based upon their professional experience and expertise. This was not, however, esteem celebrated in the abstract through say a managerial enthusiasm for symbolic rewards. Indeed, little individual acclaim was attached to any particular contribution. Rather, such recognition represented a collective appreciation of the legitimate capacity of individual officers to apply their skills and accumulated knowledge to the solving of practical organizational problems. It allowed officers sufficient autonomy to relate positively to these qualities (Honneth, 1996; 2012) and also the right to freely express them through the medium of the pilot and the feedback mechanisms attached to it, including our interviews.

What was frequently emphasized by officers during these interviews was a positive reaction to what they considered a significant and genuine improvement in the organizational culture of the two forces. The pilot demonstrated what was felt to be an overdue respect for their right to communicate valuable experience and views. Take for example, the contribution of one constable who observed that:

In 28 years in this job, you're the first person that's ever asked me what I think about the IT, and that's a momentous occasion for me, because somebody's actually taken the time to ask my opinion on something... And to be able to have that feedback is what will make it work.

It appeared that our interviewees considered the trial to be a genuine effort not only to understand the needs of frontline officers but to recognize the worth of their expertise and understanding the demands of frontline policing.

It was also evident that the officers also acknowledged the outcome of a further felt sense of recognition; namely that of self-confidence. While for Honneth (1996: 94) such self-confidence develops from the experience of what he terms the 'strong emotional attachments' of love, what is suggested here is somewhat different. Rather, we observed the emergence of a sense of self-confidence which was not mediated through individual love as Honneth (1996) might understand it, but rather through a series of institutional innovations associated with the pilot. These innovations included the presence of neutral and, interestingly, institutionally detached academic researchers which premised that the honest expression of one's needs will not lead to rejection. The substitution this offered allowed the officers a sense of trust in the collective arrangements that mimicked the individual relationship through a form of institutional love. The fact that researchers external to the police had been invited to talk with them, and objectively evaluate and report on their experiences, suggested not only respect and esteem, but a level of trust and the possibility of openness that had not been experienced previously. As one officer of over twenty years' service explained:

...the fact that you guys have come in in your capacity, and I think the reason you've had such a candid response from officers is because there is no right to reply in [the] Police, not if you're being critical of what's being done... So, it's refreshing to now have you guys come in and listen, and hopefully this will filter back and enable us to get a better job through the technology.

Thus, while acknowledging that critical feedback was perceived as seldom welcome by senior officers, there was a general sense that this initiative represented a positive development in the relationship between senior and front-line officers; one that in itself contributed to a willingness amongst the officers to support the technology despite a host of previously uninspiring encounters with similar initiatives.

\section{Discussion}

The above, reports on the response of a sample of UK police officers during an organizational initiative to introduce 'mobile policing technology'. Integral to this initiative was the operation of a pilot roll-out of the associated equipment and applications led by junior and mid-ranking officers, and utilising external academic researchers to collect and analyse confidential, qualitative feedback, on all aspects of both the usability of the technology itself as well as the operation of the pilot and associated processes. 
What we observed during our study of this process was that the initiative proved to be successful largely due to adopting what was indirectly perceived by officers as a vocabulary of trust, respect and esteem; key modalities of recognition. Alongside opportunities for meaningful collaboration, these modalities allowed front-line officers decision making power, which provided an important means for anticipated obstacles to be overcome. Traditionally advocated models of change are underpinned by employee involvement initiatives which explicitly recognize employee performance or commitment may be received as 'hollow' or 'manipulative' (Bordia et al 2011; Furst \& Cable, 2008) in organizations with history of failure. This paper argues that by recognizing and valuing the experience and knowledge of their officers, the initiative gained support and also improved the relationship dynamics between senior police management and front-line officers.

It would be amiss, of course, to draw too heroic a conclusion from this. Even leaving aside the usual caveats about small sample sizes and the limits of interpretation, there is much to be said about context here. The question as to whether or not such principles and proposals can be carried over into other organizational forms remains open. Nor can some of our opening observations pertaining to the fundamentally radical characteristics and priorities of recognition theory be ignored. As Honneth (2012) has argued, the contemporary organization of work with its increasingly narrow emphasis on the instrumental pursuit of value creation has become ill-equipped to offer recognition as anything more than a form of ideology; one designed to increase control rather than offer authentic autonomy and empowerment.

Nonetheless, in the field of management and organization scholarship (Islam, 2012; Hancock, 2014), there is some awareness of the value that can be achieved by recognizing the rights and contribution of employees through greater levels of active engagement and trust within the workplace. As we have seen through our data, the sense that officers had achieved, what for them, was a meaningful degree of influence over the organization of their work tasks resulted in a felt sense of esteem and respect in particular; both integral modalities of recognition (Honneth, 1996, 2007).

Whether or not this proves to be a palatable, and indeed practical, path for other organizations to follow, especially when undertaking larger and broader-scale change initiatives, is difficult to discern at this point in time. Yet if adopted and shown to be effective, it opens up a number of avenues for understanding the role of management within workplace life as more participatory and of greater utility to both society and the sense of well-being amongst employees across the organizational spectrum.

As a contribution to practice this research suggests that, particularly within discipline-based organizations where a culture of command and control and the politics of a deeply embedded professional identity can exacerbate change inertia and resistance, strategic advantage might be accrued by extending both symbolic and operational recognition to employees based on their accumulated experience, insight, and loyalty.

\section{Conclusion}

By drawing on ideas of Honneth $(1996,2007,2012)$ our approach draws attention to how a perceived sense of recognition contributed to a successful change initiative. Specifically, it has focused on the particular needs evident when seeking to undertake change within a hierarchical organization such as the police with a tradition of resistance to such initiatives. Officers appeared specifically receptive to the introduction of organization practices that extended a sense of esteem in respect of their professional expertise and experience and the insights they alone could bring to the initiative. This was by virtue of their knowledge of the limitations displayed by previous efforts to introduce similar communication technologies to frontline policing, alongside the everyday demands that would be placed on the technology itself.

Most interestingly, was the value placed upon a sense of self-confidence enjoyed by the officers that their views and opinions could be expressed without fear of reprisal or recrimination by virtue of the involvement of our academic team and the guarantee of anonymity this provided. Rather than simply 
reflecting a model of institutional protection, this represented a mechanism that facilitated recognition in the form of, to reapply Honneth's terminology, 'institutional love' enabling front-line officers to trustfully, and constructively engage with change, within a hierarchical and disciplinary organizational environment.

\section{References}

Bordia, P., Restubog, S. L. D., Jimmieson, N. L., \& Irmer, B. E. (2011). Haunted by the past: Effects of poor change management history on employee attitudes and turnover. Group \& Organization Management, 36(2), 191-222.

Byrne, J. and Marx, G. (2011-13) 'Technological innovations in crime prevention and policing. A review of the research on implementation and impact'. Cahiers Politiestudies (20): 17-40.

Coch, L. \& French, J.R.P. (1948) 'Overcoming resistance to change’. Human Relations, 1(4): 512-532.

Cropanzano, R., Prehar, C. A., \& Chen, P. Y. (2002). Using social exchange theory to distinguish procedural from interactional justice. Group \& Organization Management, 27(3), 324-351.

Cutcher, L. (2009) 'Resisting change from within and without the organization'. Journal of Organizational Change Management, 22(3): 275-289.

Dirks, K. T., Cummings, L. L., \& Pierce, J. L. (1996). Psychological ownership in organizations: conditions under which individuals promote and resist change. In R. W. Woodman \& W. A. Pasmore (Eds.), Research in organizational change and development (Vol. 9, pp. 1-23). Greenwich, CT.: JAI Press.

Ford, J. D., Ford, L. W., \& McNamara, R. T. (2002). Resistance and the background conversations of change. Journal of Organizational Change Management, 15(2), 105.

Fuchs, S., \& Prouska, R. (2014). Creating positive employee change evaluation: The role of different levels of organizational support and change participation. Journal of Change Management, 14(3), 361383.

Furst, S. A., \& Cable, D. M. (2008). Employee resistance to organizational change: Managerial influence tactics and leader-member exchange. Journal of Applied Psychology, 93(2), 453-462.

Grierson, J. (2017) 'Watchdog says police cuts have left forces in "perilous state". The Guardian, March 2nd.

Habermas, J. (1987a), The Theory of Communicative Action, Volume One: Reason and Rationalization of Society. Polity Press, Cambridge.

Habermas, J. (1987b), The Theory of Communicative Action, Volume Two: The Critique of Functionalist Reason. Polity Press, Cambridge.

Hancock P (2014) 'Being Santa Claus': the pursuit of recognition in interactive service work. Work, Employment and Society 28(1): 1004-20.

Holtgrewe, U. (2001), "Recognition, intersubjectivity and service work: Labour conflicts in call centres", Industrielle Beziehungen, Vol. 8 No. 3, pp.37-55.

Honneth A (1996), The Struggle for Recognition: The Moral Grammar of Social Conflicts. Polity, Cambridge. 
Honneth, A. (2007), Disrespect: The Normative Foundations of Critical Theory. Polity: Cambridge.

Honneth, A. (2012), The I in We: Studies in the Theory of Recognition. Polity: Cambridge.

Hoque, Z., Arends, S. and Alexander, R. (2004) 'Policing the police service'. Accounting, Auditing \& Accountability Journal, 17(1): 59-84.

Islam, G. (2012) 'Recognition, reification and practices of forgetting: Ethical implications of Human Resource Management'. Journal of Business Ethics. 11(1): 37-48.

Jenniges, S. (2018) Recognition Rebooted: A SMARTER Approach to Employee Recognition. Mill City Press: Minneapolis, MN.

Klausen, J. (2009) 'British counter-terrorism after 7/7: Adapting community policing to the fight against domestic terrorism'. Journal of Ethnic and Migration Studies, 35(3): 403-420.

Koper, C. S. et al. (2015) Realizing the Potential of Technology in Policing: A Multisite Study of the Social, Organizational, and Behavioral Aspects of Implementing Policing Technologies. George Mason University: Fairfax, VA.

Lindsay, R., Cooke, L. and Jackson, T. (2009) 'The impact of mobile technology on a UK police force and their knowledge sharing'. Journal of Information and Knowledge Management, 8 (2): 101-112.

Marcelo, G. (2013) 'Recognition and critical theory today: An interview with Axel Honneth'. Philosophy and Social Criticism 39(2): 209-221.

Marx, K. (1971) Karl Marx: Early texts. Ed. D. McLellen. Oxford: Blackwell.

Mead, G.H. (1934) Mind, self, and society from the standpoint of a social behaviorist. Ed. C.W. Morris. Chicago: Illinois: University of Chicago Press.

Miles, M. B. and Huberman, A. M. (1994) Qualitative Data Analysis. Thousand Oaks, CA: Sage.

Morgan, D., \& Zeffane, R. (2003). Employee involvement, organizational change and trust in management. International Journal of Human Resource Management, 14(1), 55-75.

Skogan, W. G. (2008) 'Why reforms fail' Policing and Society, 18(1): 23-34.

Skolnick, J. (1966) Justice Without Trial, New York, NY: John Wiley.

Surette, R. (2015) 'Performance crime and justice', Current Issues in Criminal Justice, 27(2): 195.

Thomas, R. \& Hardy, C. (2011) 'Reframing resistance to organizational change. Scandinavian Journal of Management, 27(3): 322-331.

Timming, A. R. (2012). Tracing the effects of employee involvement and participation on trust in managers: An analysis of covariance structures. The International Journal of Human Resource Management, 23(15), 3243-3257.

Wanberg, C. R., \& Banas, J. T. (2000). Predictors and outcomes of openness to changes in a reorganizing workplace. Journal of Applied Psychology, 85(1), 132

White, V. \& Robinson, S. (2014) 'Leading change in policing: Police culture and the psychological contract'. The Police Journal, 87(4): 258-269. 
Williams, R.R. (1992) Recognition: Fichte and Hegel on the Other. SUNY: Albany, NY. 
Table $\mathrm{X}-\mathrm{xxx}$

\section{Honneth's (1996) patterns of recognition}

\section{Love/Self Confidence} number of people' (Honneth, 1996: 95)

- Opportunity for individuals to experience a 'felt assurance that the loved one will continue to care even after he or she has become independent' (Honneth, 1996: 107)

- Basis for a sense of sense of intersubjective trust, security, and self-confidence developed through others.
- Love refers to any 'strong emotional attachments among a small

- $\quad$ Shifting to a culture of trial and

\section{Respect/Self Respect}

- Respect of universal rights usually guaranteed through the mediation of the state or other formal expressions of a shared or legitimate will

- Self-respect emerges from the intersubjective experience of bearing such rights alongside other rights bearers, defining one's own right to partake fully in the life of the polity

- Unlike love, this derives from the existence of a relatively formal and abstract relationship to the self-sustained and enacted through collective agreements.

\section{Social Esteem/Self Esteem}

- Social esteem is the recognition of the contribution that an individual, or a group's skills and abilities, contribute to the common good

- $\quad$ Self-esteem derives from the inter-subjective experience of such positive valuation and the opportunity to 'relate positively to [one's] concrete traits and abilities' (Honneth, 1996: 121)

- Most contextually variable aspect of recognition due to the fact that what is valued as deserving of esteem is reliant upon shifting fashions, values and the power of any given social group.

\section{Data interpretation}

- $\quad$ Strong personal relationship with mid-ranking and junior officers

- Being able to honestly express doubt, identify problems and provide feedback

- Opportunity to talk to neutral, independent and detached parties (academic researchers) without fea of rejection error, where experimentation is valued.

\section{Illustrative quotations}

XXXX and XXXX (mid and junior ranking officers running the trial) officers are both quite happy for you to just fire off emails if you've suddenly got a problem with it or, vice versa, you've suddenly got an idea as to things you could implement and change with it. They're more than happy to receive that, and they're sending out feedback questionnaires and stuff - all stuff that I've certainly never seen with anything that we've done before

the fact that you guys have come in in your capacity, and I think the reason you've had such a candid response from officers is because there is no right to refreshing to now have you guys come in and listen..

Unlike the PDA that came in before, or the MDTs that came in before that, they were foisted on us and allegedly ready to go and then didn't work, and that caused some bad feeling, this is actually a trial that's come out to a shift to trial and see.

- Attempts to understand the legitimate needs of frontline officers - Recognition of professional status of front-line officers

- Extending right to participate in planning and decision making

- Having confidence that can expect to become interlocuters with a right to 'voice'.

- Desire for trust in accumulated nous and skills of officers

- Being listened to

- Suggests that an officer's operational experiences are worthy of esteem

- Giving officers autonomy to solve practical organisational problems.
So, when we look back at the MDT programme and we look back at PDAs, they were solutions designed, really and truthfully, by IT people and delivered by IT, without a notion of understanding the front line

What we want to do is deliver something that's driven by the front line, and that's a very, very different place than we've been before

In 28 years in this job, you're the first person that's ever asked me what I think about the IT, and that's a momentous occasion for me, because somebody's actually taken the time to ask my opinion on something... And to be able to have that feedback is what will make it work.

Officers are generally very capable, and there are so many tasks that constables and sergeants could perform, but they're not allowed to

this is the most involvement I've ever seen any of us, as officers, have in anything. Because normally it is, "This is coming in. There you go. Get on with it." Whereas this time they are listening

That (the mobile policing technology) will work, because we actually have our

it all comes down to trusting us to actually do it ourselves and trust us to do it properly. 


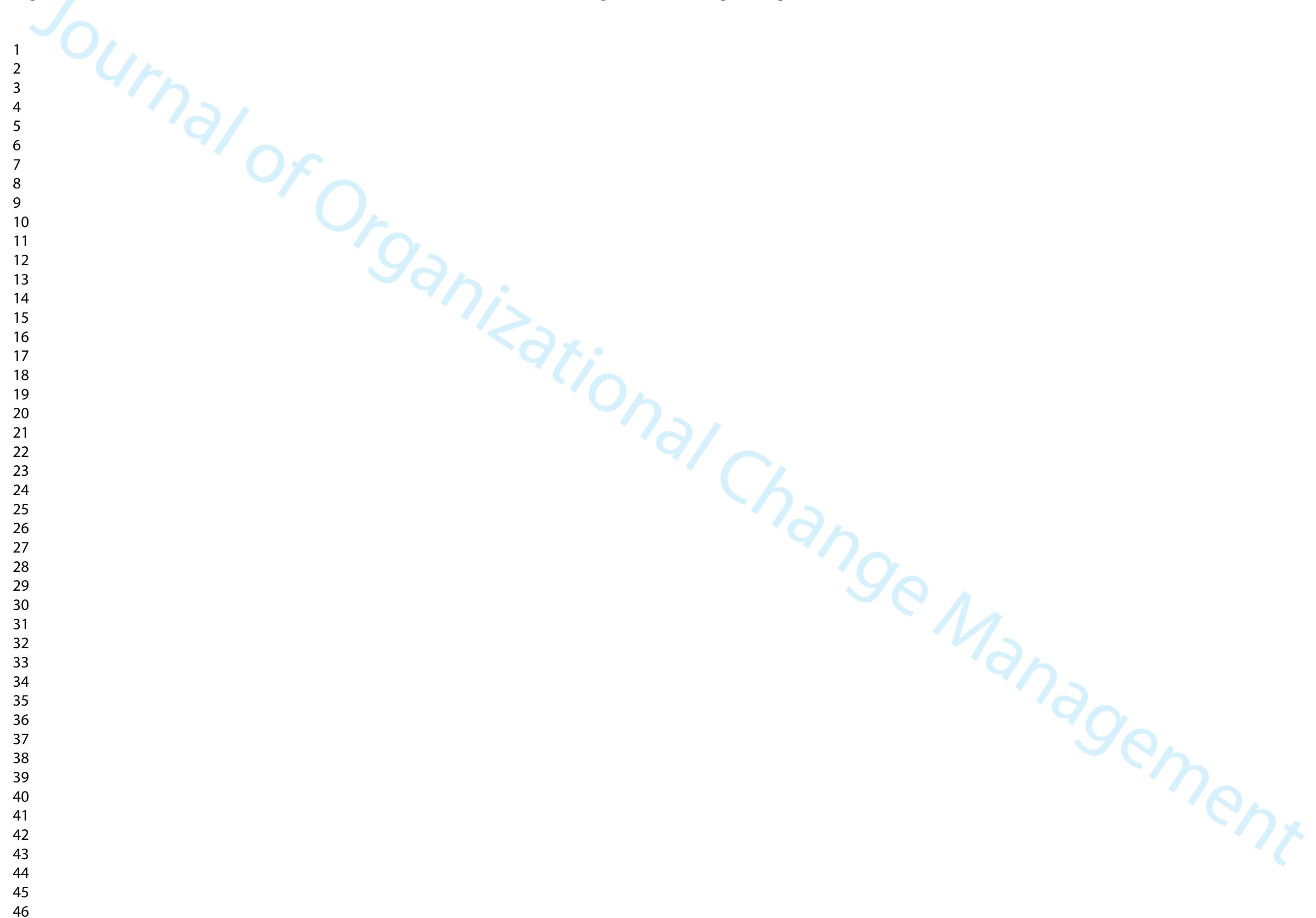

